\title{
DO TREINAMENTO E DESENVOLVIMENTO PARA A EDUCAÇÃO CORPORATIVA: TRANSIÇÕES PARADIGMÁTICAS NA CONSTRUÇÃO DO SABER NOS ESPAÇOS ORGANIZACIONAIS
}

\author{
Anicleide Pereira Silva ${ }^{1}$ \\ Florence Cavalcanti Heber \\ Pedreira Freitas ${ }^{2}$ \\ Izabel Silva Souza D'Ambrosio ${ }^{3}$
}

\section{RESUMO}

Este artigo tem como objetivo discutir a concepção de educação corporativa (EC) como um modelo emergente frente aos tradicionais processos de treinamento e desenvolvimento (T\&D) nos espaços organizacionais. Para tanto, os fios discursivos conceituais de alguns autores foram tecidos, relacionando transições e controvérsias paradigmáticas na construção do saber nos campos científicos e nos espaços organizacionais. 0 debate proposto articula as noções de modernidade e pós-modernidade no campo acadêmico, conectando-as com os conceitos e as práticas nos modelos destacados de construção do saber nos espaços organizacionais. Discutimos argumentos que sustentam a EC como sistema com status de novo paradigma de desenvolvimento de trabalhadores. Enfatizamos a importância de

1 Doutora em Administração pela Universidade Federal da Bahia, Brasil. Mestra em Educação pela Universidade Federal de Sergipe (UFS), Especialista em Controladoria pela UFS e Graduada em Administração pela UFS. Administradora na Universidade Federal de Sergipe. Áreas atuais de interesse de pesquisa são administração pública, educação corporativa, estudos organizacionais, gestão de pessoas e análise crítica do discurso.

2 Doutora em Administração pela Universidade Federal da Bahia, Brasil. Mestre em Administração pela Universidade Federal da Bahia e graduada em Sociologia pela Universidade Federal da Bahia. Atualmente é professora associada e pesquisadora na Universidade Federal de Sergipe no Programa de Pós graduação em Administração (PROPADM), e docente colaboradora no Núcleo de Pós Graduação em Administração (NPGA) da Universidade Federal da Bahia.

3 Doutoranda do Programa de Pós-Graduação em Educação pela Universidade Federal de Sergipe. Sua tese estuda sobre a realidade do ensino digital no contexto pandêmico. Mestra em Educação pela Universidade Federal de Sergipe. Área de interesse de pesquisa: Tecnologia Digital, Educação a Distância e Linguística. Graduada em Letras-Inglês pela Universidade Federal de Sergipe, Brasil. Trabalha como professora de inglês na Educação Básica - Secretaria de Educação do Estado de Sergipe. 
compreender os sentidos e (res)significações do saber na concepção de "educação" em espaços organizacionais.

Palavras-Chave: Educação corporativa; Treinamento e desenvolvimento; Transições e controvérsias paradigmáticas; Campos científico/organizacional.

\title{
DE LA CAPACITACIÓN Y EL DESARROLLO PARA LA EDUCACIÓN CORPORATIVA: TRANSICIONES PARADIGMÁTICAS EN LA CONSTRUCCIÓN DEL SABER EN LOS ESPACIOS ORGANIZACIONALES
}

\section{RESUMEN}

Este artículo tiene como objetivo discutir el concepto de educación corporativa (EC) como un modelo emergente frente a los procesos tradicionales de capacitación y desarrollo (T\&D) en espacios organizacionales. Para eso, los hilos discursivos conceptuales de algunos autores sobre transiciones y controversias paradigmáticas en la construcción del saber en los campos científicos y en los espacios organizacionales. El debate propuesto articula las nociones de modernidad y posmodernidad en el campo académico, relacionándolas con los conceptos y las prácticas en los modelos destacados de construcción del saber en los espacios organizacionales. Discutimos argumentos que respaldan la EC como sistema con el estatus de un nuevo paradigma de desarrollo de los trabajadores. Hacemos hincapié en la importancia de comprender los sentidos y (re)significados del saber en la concepción de la "educación" en los espacios organizacionales.

Palabras clave: Educación corporativa; Entrenamiento y desarrollo; Transiciones y controversias paradigmáticas; Campos científicos / organizacionales.

\section{FROM TRAINING AND DEVELOPMENT TO CORPORATE EDUCATION: PARADIGMATIC TRANSITIONS IN THE KNOWLDGE BUILDING IN ORGANIZATIONAL SPACES}

\begin{abstract}
This paper aims to discuss the corporate education (CE) concept as an emerging model toward traditional training and development (T\&D) processes in organizational spaces. Therefore, the conceptual discursive threads of some authors were interlaced relating paradigmatic transitions and controversies in the knowledge building in scientific fields and in organizational spaces. The proposed debate articulates modernity and post-modernity notions in the academic field, connecting them with concepts and practices in the highlighted models of knowledge construction in organizational spaces. Arguments for supporting CE as a system were debated among us with the status of a new worker development paradigm. The importance of understanding the senses and re-signifying knowledge was emphasized in the "education" conception in organizational spaces.
\end{abstract}


Keywords: Corporate education; Training and development; Paradigmatic transitions and controversies; Scientific / organizational fields.

\section{INTRODUÇÃO}

O mundo vem passando, a partir do século $X X$, por um processo de transição da modernidade para a pós-modernidade que não se traduz apenas em uma delimitação das tendências onto-epistêmico-metodológicas marcantes da ciência e da pesquisa científica, mas da própria essência da construção do saber ${ }^{4}$ e dos desafios pelos quais passa a sociedade nessas transições e, especificamente para este estudo, o campo das práticas educativas nas organizações ${ }^{5}$ do trabalho.

Buscando entender esse processo, resgatamos as concepções de modernidade e pósmodernidade presentes no campo científico, principalmente a partir das concepções de Boaventura Santos 6 , na obra "Um discurso sobre as ciências" (2009). O autor indica que a modernidade apresenta como principal característica a tentativa de consolidar a ciência a ser constituída a partir da revolução científica do século XVI. Mas também por uma compreensão sobre a mudança de uma ordem tradicional para uma moderna, na perspectiva dos sociólogos germânicos do século XIX e XX, centrada no desenvolvimento industrial capitalista.

40 termo saber, segundo Santos (2000), é tomado como sinônimo de conhecimento. É nesse sentido que o empregamos neste artigo, mais especificamente do conhecimento gerado nos espaços de trabalho. No entanto, ressalta-se ainda que para o autor, "a opção por um ou outro tem implicações de várias ordens. Conhecimento é utilizado quando se quer referir ao saber científico, ou ao saber formalizado, socialmente legitimado. Já o saber, via de regra, tem uma conotação mais pejorativa [...]. No entanto, um debate atual, coloca na ordem do dia a necessidade de resgatar as dimensões esquecidas dos saberes chamados menores elevando-os à maioridade." (SANTOS, 2000, p. 295).

5 Considera-se organização aqui no sentido ampliado de empresa e/ou corporação, com objetivos econômicos ou não econômicos, pública ou privada.

6 É preciso esclarecer que Boaventura Santos adverte em seus estudos (SANTOS, 1997) que usa o termo pósmoderno mesmo julgando-o inadequado. 0 autor observa: "Como todas as transições são simultaneamente semicegas e semi-invisíveis, não é possível nomear adequadamente a presente situação. Por esta razão lhe tem sido dado o nome inadequado de pós-modernidade. Mas, à falta de melhor, é um nome autêntico na sua inadequação" (p. 77). Explica que por esta razão designa sua proposta de paradigma pós-moderno como pósmodernismo de oposição (SANTOS, 2008). 
Um período caracterizado como a era da racionalidade, desenvolvida basicamente sob o domínio das ciências naturais, advogando uma razão que se coloca como absoluta e objetiva, afastando a cultura dos objetos ou dos poderes transcendentais, religiosos ou metafísicos (SANTOS, 2009). Essa racionalidade vai fundamentar não apenas o campo do conhecimento científico, cuja base é a ciência positivada, mas também a vida social, a arte, a ética, a moral e as relações sociais e de trabalho (GATTI, 2005).

A partir do século XX, entretanto, novos fatos socioculturais, em todos os campos sociais, levaram estudiosos a caracterizá-los como pós-modernos, revolucionando inclusive as ciências e as formas de lidar com as teorizações e as linguagens (HARVEY, 2008; SANTOS, 2009). De acordo com Santos (2009, p. 78-79), "A ciência pós-moderna não segue um estilo unidimensional, facilmente identificável; o seu estilo é uma configuração de estilos construída segundo o critério e a imaginação pessoal do cientista”. Entende que há entre esses períodos de modernidade e pós-modernidade uma dualidade paradigmática que culmina em suas concepções dos paradigmas dominante e emergente.

Segundo defendem alguns estudiosos, como postula Gatti (2005), o século XX não nos fez viver momentos nem de ruptura, nem de continuidade cronológica com o paradigma moderno ou pós-moderno. Passamos, a partir de então, para o movimento de conflitos e contradições, entre um pensamento e outro, uma vez que se vive em ambos ruptura e continuidade. Alguns estudiosos consideram que essa era já surgiu como pós-moderna e é marcada pelas mudanças, pela imprevisibilidade, pela velocidade, pela realidade virtual, pela cultura informatizada, televisiva e por uma linguagem imagética (CASTELLS, 1999; HARVEY, 2008).

Ao analisar conceitos sobre modernidade e pós-modernidade, Parker (1995) sinaliza que o prefixo incluído no segundo é também o identificado em conceitos associados como pós-fordismo, pós-industrial, pós-capitalismo e que todos se remetem a ideia de uma nova era, novo momento histórico em transição. 
Esses processos e discussões da transição da modernidade para a pós-modernidade se traduzem em uma delimitação das tendências marcantes também no campo das práticas organizacionais. Em decorrência disso e para atender aos novos desafios impostos ao mundo do trabalho (HARVEY, 2008), as organizações se veem compelidas a implantar novos modelos de gestão que privilegiem o desenvolvimento de conhecimento e aprendizagem em seus espaços organizacionais (EBOLI, 2004; MEISTER, 1999). A criação de processos e sistemas visando a qualificação e aquisição de competências profissionais dos trabalhadores tornam-se práticas estratégicas para alavancar resultados e vantagens competitivas das organizações. Nesse contexto, a concepção de Educação Corporativa (EC) é apresentada como novo modelo de construção do conhecimento frente aos tradicionais processos de treinamento e desenvolvimento (T\&D), principalmente nas grandes corporações transnacionais com altos investimentos em inovações tecnológicas (EBOLI, 2004, 2016; MEISTER, 1999).

A disseminação da ideia de um novo modelo educacional e de construção do saber nos espaços organizacionais, especialmente a partir do final do século XX (EBOLI, 2004; MEISTER, 1999; MUNDIM; RICARDO, 2009; WHEELER, 2005), cria também controvérsias paradigmáticas para os campos dominantes do saber, como os acadêmico-científicos, e toda a rede de atores sociais inseridos nesses sistemas, como docentes, pesquisadores, mas também gestores de organizações, consultores de cursos de negócios e autores de livros especializados na área de gestão.

Diante dessas (re)configurações, entretanto, surgem ressignificações de conceitos e métodos de geração e disseminação de saberes nos espaços organizacionais. Nesse sentido, com a intenção de contribuir com essas reflexões, o presente estudo tem como objetivo refletir sobre a concepção de educação corporativa como um modelo emergente frente aos processos de treinamento e desenvolvimento, na construção do saber nos espaços organizacionais.

Para tanto, o artigo está composto, além desta introdução e considerações finais, de mais duas seções. Na primeira seção são discutidas transições e controvérsias regidas pelos 
paradigmas dominante/emergente na construção do saber científico. Na segunda seção, formada por duas subseções, seguimos o caminho que tece os paradigmas da construção do saber nos espaços organizacionais de trabalho, entrelaçando os fios da transição entre o mundo do trabalho e o saber funcional do treinamento à concepção de educação corporativa.

\section{TRANSIÇõES E CONTROVÉRSIAS PARADIGMÁTICAS DA CIÊNCIA E DA PESQUISA NA CONSTRUÇÃO DO SABER}

As controvérsias paradigmáticas das ciências destacam questionamentos que emergem sobretudo a partir dos anos 1970 e 1980, tendo como estopim, segundo Santos (2009, p. 11), a "Guerra das Ciências". Essas questões promovem uma desnaturalização da ciência enquanto espaço de neutralidade e campo autônomo e descolado da sociedade e suas influências, sejam essas políticas, ideológicas, religiosas. Por outro lado, as transformações sociais advindas com a transição da modernidade para a pós-modernidade, fazem com que a sociedade perceba a ciência como um espaço para construção de novas compreensões sobre o passado, o presente e os futuros possíveis.

Para traçar os fios que regem as questões paradigmáticas e suas crises no campo da ciência, vamos iniciar com um breve caminhar pelas concepções de paradigma que entendemos conduzir a algumas significações diferentes nas suas acepções clássica e contemporânea. 0 sentido clássico nos remete ao entendimento pela filosofia de Platão, que designa o termo paradigma evocando o conceito de modelo e, nesse sentido, o termo pode ser considerado como equivalente ao de ideia, que em grego tem a raiz etimológica procedente como o verbo ver, equivalente a visão, mas não apenas a visão que alguém tem de algo, e sim do aspecto oferecido pela coisa vista (PLASTINO, 2005).

Segundo explica Marcondes (2005, p. 14), “A noção de paradigma deve ser assim entendida como uma das versões da teoria platônica das Formas ou Ideias, e tem, portanto, um sentido ontológico forte, designando aquilo que é real, o ser enquanto causa, determinante do que existe no mundo concreto, dele derivado". Entende que esse significado 
platônico atribui um caráter normativo ao paradigma que será importante na acepção contemporânea.

$\mathrm{Na}$ acepção contemporânea, o emprego do conceito de paradigma para analisar o desenvolvimento das ideias científicas nos remete aos estudos de Thomas Kuhn. As ideias Kuhnianas abrangem uma "constelação de crenças, valores, técnicas, etc., partilhadas pelos membros de uma comunidade" científica e utilizada por essa comunidade para definir problemas e soluções legítimas (KUHN, 2011, p. 218).

Caracteriza a evolução das ciências através da especialização, do crescimento da separação das disciplinas científicas e de uma condução do científico que o faz se desvencilhar das questões gerais vinculadas à significação global de suas pesquisas, restringindo-se aos problemas específicos de uma disciplina. Esta concepção pressupõe, também, um trabalho científico autônomo em relação às questões culturais, econômicas e sociais do contexto de realização desse mesmo trabalho (KUHN, 2011).

Nesse sentido, a repercussão das ideias de Kuhn ultrapassou os limites da filosofia da ciência, ensejando debates em diversas outras disciplinas. Nos reportando a área dos estudos organizacionais, temos, por exemplo, Burrell e Morgan (2005) que se baseiam na lógica e nas ideias Kuhnianas para conceber seu modelo paradigmático. Entendem que os paradigmas são definidos por premissas metateóricas que ratificam os modos de teorização, os quadros de referência e o modus operandi dos cientistas que orbitam em torno deles. Isso possibilita perspectivas comuns que permitem considerá-los como uma abordagem da mesma problemática, mesmo que não implique uma unidade completa de pensamento (BURRELL; MORGAN, 2005).

A partir dos anos 70 vários teóricos buscaram classificar os paradigmas de pesquisa nas ciências sociais, políticas e educacionais (SANTOS FILHO; GAMBOA, 2007). Habermas (1983), por exemplo, baseado numa tipologia do interesse humano, entende que os três enfoques básicos da investigação: o empírico-analítico (interessado na compreensão do mundo físico); o histórico-hermenêutico (preocupado com o significado dos eventos 
históricos); e o crítico-dialético (orientado para a exposição das condições de opressão e dominação); orientam as categorias de produção do conhecimento humano, tais como, respectivamente: o técnico de controle (trabalho-técnica-informação), o dialógico de consenso (linguagem-consenso-interpretação) e o crítico emancipador (poder-emancipaçãocrítica).

De acordo com Plastino (2005), a produção de conhecimentos ocorre então pela aplicação a questões e novos problemas do paradigma considerado, o que provocaria suas crises. Por essa razão, a crise do paradigma intervém quando o conjunto de conceitos e técnicas que o formam fracassa reiteradamente na solução de questões de seu próprio âmbito de pertinência, promovendo obstáculos epistemológicos e rupturas epistemológicas (KUHN, 2011). Ao instalar paradoxos na capacidade explicativa de produção de conhecimento quebram a homogeneidade da comunidade científica e instala debates, embates, soluções e outras alternativas na produção de conhecimento com vistas ao estabelecimento de um novo paradigma e pelo restabelecimento da homogeneidade em torno dele (novos tempos "normais", na acepção Kuhniana).

No entanto, Plastino (2005) entende que se faz necessário discutir tanto a questão da crise de determinado paradigma (SANTOS, 2009), quanto a crise do conceito mesmo de paradigma. Entende que não é de uma crise dos paradigmas que se deve falar, pois não se trata de substituir um modelo que se apresenta incapaz de refletir uma realidade dada. 0 que se enfrenta é a crise do conceito mesmo de paradigma, na medida em que não existindo uma realidade dada, entendida como sistema fechado, já não se trata de discutir a maior ou menor pertinência de um modelo ou paradigma que a reflita, mas é preciso criticar a pertinência do próprio conceito de paradigma. Esta segunda perspectiva inclui a crítica do conceito de crise dos paradigmas, uma vez que, ao contrário do modelo positivista, essa crise não deriva da inadequação dos paradigmas a uma realidade, mas de sua incompatibilidade com nossas escolhas éticas (PLASTINO, 2005) ou, em outras discussões, com visões de mundo (BURRELL; MORGAN, 2005; MORGAN, 2005). 
A crise do paradigma significaria assim, segundo Plastino (2005), questionar a especialização das disciplinas científicas e sua autonomia frente ao contexto global de sua produção, ou seja, as problemáticas sociais, econômicas, políticas e culturais das sociedades nas quais esta produção acontece. A questão central que atravessa a crise do paradigma da ciência moderna é a das relações entre a permanência e a mudança. Questiona também a crescente especialização, formalização, por vezes a matematização e a pretensa autonomia das construções científicas, em relação ao contexto global de sua produção. Entende que essas construções científicas formam outros traços marcantes que as ciências sociais tomaram dos paradigmas científicos das ciências naturais da modernidade.

De acordo com Santos (2009), a ciência social será sempre uma ciência subjetiva e não objetiva como as ciências naturais. Compreende os fenômenos sociais a partir das atitudes mentais e dos sentidos que os agentes conferem às suas ações, para o que é necessário utilizar métodos de investigação e mesmo critérios epistemológicos diferentes. Esta concepção de ciência social se reconhece numa postura antipositivista e assenta na tradição filosófica da fenomenologia e nela convergem diferentes variantes, desde as mais moderadas (como a de Weber) as mais extremistas (como a de Winch).

Hoje são muito fortes os sinais de que o modelo de racionalidade científica atravessa uma profunda crise, intitulada por Santos (2009) como sendo a crise do paradigma dominante. É o resultado interativo de uma pluralidade de condições que não é só profunda, mas irreversível. Explica que estamos vivendo um período de revolução científica que se iniciou com Einstein e a mecânica quântica; na microfísica, com Heisenberg e Bohr e suas demonstrações de que não é possível analisar um objeto sem que a mera presença do observador o afete; e muitas outras, desconhecendo seu fim. Entende que os sinais nos permitem não só especular acerca do paradigma que surgirá desse período revolucionário, mas que, desde já, pode-se afirmar com segurança que colapsarão as distinções básicas em que assenta o paradigma dominante. 
Superando as ideias dominantes, Santos (2009) explana sobre a concepção que define como paradigma emergente um conjunto de quatro teses seguidas de justificação. Em primeiro, diz que todo conhecimento científico-natural é científico-social e que a distinção dicotômica entre ciências naturais e ciências sociais deixou de ter sentido e utilidade. Em segundo, afirma que todo conhecimento é local e total. Em seguida, apresenta que todo o conhecimento é autoconhecimento. E na quarta tese, diz que todo conhecimento científico visa constituir-se em senso comum, que faz coincidir causa e intenção, que é prático e pragmático, é transparente e evidente, é interdisciplinar e imetódico. É superficial. Aceita o que existe tal como existe. É retórico e metafórico.

Em sua fase de desenvolvimento, as ciências humanas e sociais tenderam a demarcarse umas em relação às outras, cada uma tendo suas próprias áreas de estudos (psicológica, econômica, cultural). Isso, hoje, não significa mais isolar os estudos em caixas de especialidades e/ou campos das ciências. Muito pelo contrário, entrelaçar esses fios de forma inter, trans e multidisciplinar se torna cada dia mais imprescindível para interpretar e refletir sobre os problemas decorrentes das transformações pelas quais passam as sociedades contemporâneas.

Dessa forma, estudos em determinadas áreas científicas vem debatendo novos caminhos para as questões paradigmáticas entre os campos especializados das ciências (BURRELL; MORGAN, 2005; SANTOS, 2009). Dentre essas perspectivas, temos inserido também o crescimento de campos científicos como os da Administração/Negócios e os Estudos Organizacionais (EORs). Estes, por sua vez, geram estudos sobre os fenômenos organizacionais e suas relações com o mundo social e o mundo acadêmico-científico (MEDEIROS; TEIXEIRA, 2018; ALPERSTEDT; ANDION, 2017; MOTTA, 2017), como as mudanças paradigmáticas do saber produzido no mundo do trabalho. Imbrincados nas mudanças na sociedade, o campo de estudos organizacionais é também o campo onde a reflexão sobre os fenômenos organizacionais ocorre em meio a controvérsias, é um campo de disputas de "visões de mundo" (BURRELL; MORGAN, 2005). 
No entanto, para Leal (2002), grande parte da teoria organizacional é ainda sustentada no projeto modernista baseado no iluminismo e no empirismo. Sustentada por princípios gerenciais baseados na racionalidade instrumental que se opõe à razão crítica. E quando a razão se torna instrumental, alinha a ciência a instrumento de poder, de dominação, de exploração. A racionalidade instrumental, ou razão instrumental, é um aspecto dominante das teorias e práticas organizacionais (MOTTA; THIOLLENT, 2016; SERVA et al., 2015) e das sociedades contemporâneas. Nesse campo das práticas e dos estudos voltados às organizações, a pós-modernidade parece requisitar novas formas de pensar e agir, novas epistemologias, novos referenciais teóricos, novas formas de abordagem e metodologias para problemas organizacionais, como assinalam Cooper e Burrell (1988).

Castells (1999, p. 197) já indicava reflexos da flexibilização da produção e das novas formas de gerenciamento em organizações e observava "a crise do modelo corporativo tradicional baseado na integração vertical e no gerenciamento funcional hierárquico: o sistema de 'funcionário e linha' de rígida divisão técnica e social do trabalho dentro da empresa". E também que na forma de produção flexível, o trabalho cooperativo entre os gerentes e os trabalhadores representaria o novo tipo de relação fundado nesse momento histórico, uma nova base prática. Nesse processo, “[...] a característica central e diferenciadora do modelo japonês [de flexibilidade] foi abolir a função de trabalhadores profissionais especializados para torná-los especialistas multifuncionais" (CASTELLS, 1999, p. 180).

Compreender essas transformações nas sociedades contemporâneas parece requisitar do campo acadêmico posturas mais integrativas entre distintas áreas do conhecimento científico, investimentos que se caracterizem pela articulação de diferentes olhares e perspectivas. E, talvez, nos estudos organizacionais, o reconhecimento (enfim) da pluralidade epistemológica que caracteriza o campo (BURRELL; MORGAN, 2005) fosse o primeiro passo para trajetórias de pesquisa e construção de saber requeridas na pós-modernidade.

Nos estudos organizacionais, Clegg (1990) afirma que na pós-modernidade, num mundo caracterizado como pós-moderno, as organizações mecanicistas, burocráticas e 
tayloristas perderam espaço para outras formas organizacionais mais criativas, caracterizadas pela presença de grupos de trabalho e sistemas mais participativos e autônomos (autocontrolados). E também que nessas organizações, que ele denominou pósmodernas, as estruturas organizacionais seriam mais flexíveis e, do ponto de vista do trabalho, as exigências de múltiplas habilidades seriam a tônica.

As propriedades simbólicas das organizações são enfatizadas no vasto e complexo campo dos estudos sobre cultura organizacional. Influências epistemológicas nos estudos organizacionais também sugerem que o mundo é constituído por linguagens compartilhadas e que só podemos conhecê-lo através dos discursos que nossa linguagem cria para compreender e intervir nas organizações (HASSARD, 1993).

Nesse caminhar, as controvérsias entre a tradição onto-epistêmica-metodológica baseada na tradição positivista e a emergência de posturas antipositivistas na construção do saber (SANTOS, 2009) proporcionam situações distintas de compreensão paradigmática e de produção científica, nos diversos campos das ciências e na geração de conhecimentos. E tem desdobramentos no campo organizacional, como serão discutidos a seguir.

\section{TRANSIÇÕES E CONTROVÉRSIAS PARADIGMÁTICAS NA CRIAÇÃO DO SABER NOS ESPAÇOS ORGANIZACIONAIS}

Para realizar o caminho de reflexão proposto neste estudo, vamos trilhar esta seção enfocando, primeiro, as transições no mundo do trabalho que levaram as organizações às práticas de processos de criação de saber sistematizados e estratégicos, visando dotá-las de maior eficiência e eficácia. Nesse sentido, enfocamos na segunda subseção que essas práticas são disseminadas pelos campos do management e dos estudos científicos organizacionais como mudanças paradigmáticas dos processos de treinamento e desenvolvimento, as quais resultam na concepção conceitual de educação corporativa. 
De todas as transformações pelas quais o mundo vem passando desde o século XX mudanças econômicas, sociais, políticas, culturais e tecnológicas - uma das esferas em que mais se percebem essas mudanças é o mundo do trabalho, com a substituição de um modo de produção rígida - o modelo taylorista-fordista - por um modelo de produção assentado na especialização flexível.

Assim como ocorre com as demais transformações paradigmáticas pelas quais as sociedades vêm passando na transição dos períodos entendidos como modernização e pósmodernização (SANTOS, 2009), o mundo do trabalho enfrenta muitos desafios. Nesse percurso, procurando responder por mudanças quantitativas e qualitativas, campos da ciência - como a sociologia, a educação do trabalho, os estudos organizacionais e outras áreas do conhecimento -, debatem as origens, desenvolvimento e destino dessas transformações.

Nessa transição, com os sistema produtivo e de gestão baseado em especialização flexível, que teve grande impulso com essas mudanças, decorre a superação do paradigma taylorista-fordista. A crise do sistema fordista, por sua vez, foi deflagrada externamente à produção capitalista, isto é, na demanda e no consumo de produtos. A produção em massa de produtos rígidos e estandardizados teria esbarrado em mercados cada vez mais saturados. A resposta a essa crise parte de uma certa recuperação de elementos ou formas produtivas que sucumbiam diante do sistema fordista, sem se extinguir (HARVEY, 2008). Para Eboli (2004, p. 36), "A troca de paradigma na gestão de empresas, a passagem da administração tayloristafordista para a gestão flexível, gerou forte impacto no comportamento das organizações".

Advindos de um sistema capitalista transformado, o debate se concentra nos cenários sociais que influenciam diretamente este mundo, tais como: os processos de competitividade de mercados globais; os desenvolvimentos das tecnologias digitais e comunicacionais; a transição do sistema de produção e gestão taylorista-fordista; a continuidade do fordismo; a emergência de uma forma produtiva ligada a novos padrões de demanda e à especialização flexível; os limites e possibilidades de expansão desta nova forma produtiva, que muitas vezes foi identificada com os processos que lhe serviam de base, ou o toyotismo ou modelo japonês; 
a exigência de trabalhadores com especialidades polivalentes/flexíveis; a perda da centralidade do setor industrial para o setor de serviços; o aumento do espaço de informalidade nos contratos de trabalho; o conhecimento e a educação como mercadorias, entre outros (HARVEY, 2008; LAVAL, 2004).

Para se adaptar ao mercado, nessa nova configuração capitalista, as organizações, principalmente as empresariais, tiveram que primar não só pela versatilidade dos produtos, como também pela qualidade. Para produzir produtos não rígidos, não estandardizados, as organizações teriam que buscar uma tecnologia, um complexo homem/máquina. Essa flexibilização nos processos de trabalho e gestão de negócios impõe uma aproximação das etapas de concepção, de execução e de controle baseando-se na incorporação progressiva da qualificação e competências dos trabalhadores e suas relações sociais. Ao trabalhador desqualificado ou semi-qualificado do fordismo, contrapor-se-ia o trabalhador qualificado, que teria sobre si a responsabilidade de agir qualificadamente sobre as mais diversas etapas dos processos de trabalho (HARVEY, 2008).

Nesse novo modelo o debate passa a ser em torno das exigências aos trabalhadores, em termos de sua qualificação e competências. Exige-se desses muito mais um saber-ser do que um saber-fazer, ou seja, discute-se que a qualidade humana mais desejada dos profissionais em todas as áreas é a capacidade de pensar adequadamente, ao contrário do que já foi em outras eras, em que se desejavam pessoas que não pensassem, apenas fossem capazes de realizar trabalhos repetitivos. Tais exigências fazem com que as organizações também busquem instrumentos de ensino-aprendizagem que qualifiquem seus trabalhadores de forma a mantê-las altamente competitivas no mundo globalizado (EBOLI, 2004; MEISTER, 1999).

Nessa perspectiva, a partir deste século, as características dos trabalhadores são definidas por outros valores e necessidades, porque, segundo alguns estudos, estamos vivendo em um mundo cujas competências são estabelecidas pela chamada sociedade do conhecimento (COUTINHO; LISBÔA, 2011; CASTELLS, 1999) e economia baseada no 
conhecimento (JESSOP, 2005). Para atender a essa lógica, não basta somente elaboração de estratégias que requerem mudanças tecnológicas, mas ações que causem impacto nos processos de educação, formação e competências dos empregados-cidadãos, revertendo em desempenhos eficazes e com valores diferenciados.

O novo processo de produção advindo da ruptura com os procedimentos tayloristas, baseados na racionalidade científica e instrumental (SANTOS, 2009), conduziria a atenção não apenas ao processo, mas também sobre os indivíduos e suas qualidades. Portanto, para Zarifian (2001), a atenção colocada não apenas nas qualidades que o trabalhador possuísse, mas também nas que ele poderia adquirir em um processo de produção qualificante formou o novo conteúdo das qualificações, o qual, em seu entendimento, é a aquisição contínua de competência.

Logo, competência fica definida como a capacidade de "assumir responsabilidades frente a situações de trabalho complexas [aliado] [...] ao exercício sistemático de uma reflexividade no trabalho" (ZARIFIAN, 2001, p. 42). 0 autor afirma também que "o trabalho reverte-se ao trabalhador e torna-se prolongamento direto da competência pessoal que o indivíduo mobiliza diante de uma atuação profissional [...]" (ZARIFIAN, 2001, p. 42). Confirma assim a prática de responsabilização do trabalhador por suas ações organizacionais.

Segundo explica Cruz (2005),

Zarifian e Veltez, ao tomarem como referência a relação entre trabalho e comunicação, concebem a qualificação como capacidade de lidar com o imprevisto, isto é, de agir e reagir a situações imprevisíveis, com o reconhecimento dessa capacidade pela comunidade de produtores, o que caracteriza a dimensão social da qualificação. Dessa base, focalizam uma nova concepção de qualificação como competência (CRUZ, 2005, p. 95).

Para Ferreti (2004), quando a produção capitalista passa a emprestar à flexibilidade na produção, surge em cena o elemento novo no debate sobre a qualificação, que recebe o nome de modelo de competências. Dessa maneira, segundo as perspectivas do capital, a 
noção de competência representa uma atualização do conceito de qualificação, tendo em vista adequá-lo às novas formas pelas quais ele se organiza para conseguir uma maior e mais rápida valorização.

\begin{abstract}
Contrariamente ao que se dava no taylorismo-fordismo, o saber construído pelos trabalhadores no cotidiano da fábrica passa não apenas a ser reconhecido como requisitado e premiado. 0 chamado saber tácito, ou qualificação tácita, oriundo da experiência dos trabalhadores individuais e do coletivo do trabalho, ganha proeminência porque se reconhece sua força para a resolução dos problemas diários com que a produção se defronta. A valorização desse saber e sua incorporação à produção recebem um nome - modelo de competências -, em que estas significam não apenas o saber/fazer, o domínio do conhecimento técnico, mas, principalmente, o saber/ser, a capacidade de mobilização dos conhecimentos (não apenas técnicos) para enfrentar as questões problemáticas postas pela produção (FERRETI, 2004, p. 415).
\end{abstract}

O saber se aproxima assim do conceito de competência, sendo esta tomada como uma capacidade inovativa transferível pela prática e cultura organizacional, possibilitadas então por processos formais de aprendizagem, como são articulados os processos de capacitação sistematizados. Para operacionalizar isso, as organizações passam, então, a definir competências estratégicas para o seu negócio e a "desenvolver" seus trabalhadores segundo suas necessidades produtivas. Essa nova configuração recai também sobre o sistema educacional, com mais exigências no sentido de reformulações curriculares que se integrem às necessidades do mercado de trabalho, a flexibilização e a polivalência.

De acordo com Cruz (2005),

A demanda por novas competências constitui o novo e coloca-se no âmbito da transição do velho para o novo paradigma do trabalho. É um desafio para os estudiosos do campo educacional, que exige reflexões conjuntas (empresas, trabalhadores e educadores) sobre a redefinição do conteúdo das qualificações, os níveis de saberes e habilidades necessários, de forma a contemplar os questionamentos provenientes do mundo do trabalho. Essa nova demanda por qualificação, do ponto de vista político-social, revela que o axioma do marxismo 
tradicional da desqualificação da mão-de-obra com o avanço da tecnologia está sendo rapidamente sepultado. Os estudos empíricos contradizem a tese defendida por Braverman, na sua conhecida obra Trabalho e Capital Monopolista, de que as sociedades capitalistas, com sua tecnologia, tendem a desqualificar o trabalho e a aumentar o controle do capital sobre a produção, acentuando o caráter degradante do trabalho no século XX (a separação entre concepção e execução). (CRUZ, 2005, p. 9394).

Portanto, a troca de paradigma na gestão das organizações e a passagem da administração taylorista-fordista para uma gestão flexível gerou forte impacto no comportamento das organizações. A rígida divisão entre trabalho mental e manual por meio da execução de tarefas fragmentadas e padronizadas cedeu lugar a estruturas integrais e complexas, que exigem um novo perfil de trabalhador (HARVEY, 2008).

Para criar esse novo perfil, as organizações precisam implantar programas de qualificação que privilegiem o desenvolvimento de novas competências; e, embora as instituições de Educação Formal tenham como principal função a disseminação do conhecimento aos alunos e a formação profissional legitimada, as organizações sentem a necessidade de preparar melhor seu quadro de trabalhadores para atuarem com foco em seus próprios negócios (EBOLI, 2004, 2016; MEISTER, 1999).

O discurso da educação nos espaços organizacionais difunde assim a crença no potencial humano para articular uma ordem social democrática do saber e o espaço de mobilização do indivíduo para desenvolver processos estratégicos de aprendizagem organizacional (EBOLI, 2004; MEISTER, 1999; MUNDIM; RICARDO, 2009; WHEELER, 2005).

O campo da gestão legitima não apenas visões normativas do saber-fazer, mas um modo prescritivo de como esse fazer se vincula aos sentidos atribuídos aos conceitos de eficácia e produtividade no trabalho. Propala-se que o trabalhador idealizado e almejado para o trabalho é o cidadão produtivo, dotado de força física, moralista, disciplinado, monogâmico, abstêmio, dócil, hábil e adaptável. Ou seja, o trabalhador (con)formado e moldado por um discurso extremamente adequado à forma de organização de trabalho dominante, que se 
caracteriza pela ideologia gerencialista ou do management (FARIA; LEAL, 2007; WOOD JÚNIOR; TONELLI; COOKE, 2011). Nessa lógica de construção discursiva não temos apenas o campo corporativo, como bem observa Harvey (2008), quando explica em seus estudos que

a educação, o treinamento do trabalhador, a persuasão, a mobilização de certos sentimentos sociais (a ética do trabalho, a lealdade aos companheiros, o orgulho local ou nacional) e propensões psicológicas (a busca da identidade através do trabalho, a iniciativa individual ou a solidariedade social) desempenham um papel e estão claramente presentes na formação de ideologias dominantes cultivadas pelos meios de comunicação de massa, pelas instituições religiosas e educacionais, pelos vários setores do aparelho do Estado, e afirmadas pela simples articulação da experiência por parte dos que fazem o trabalho (HARVEY, 2008, p. 119).

Nas últimas décadas, uma vasta produção discursiva do campo da gestão foi acionada para reforçar as teses da competitividade e do individualismo. Criam-se e ressignificam-se conceitos que passam a ser abundantemente utilizados na gestão do trabalho flexível. Popularizam-se conceitos como flexibilidade, competitividade e participação. Essa nova configuração produziu mudanças nas relações do mercado de trabalho e, consequentemente, no trabalhador, que deveria adequar-se às demandas de flexibilidade e empregabilidade. Como constata Harvey (2008), argumenta-se, oportunamente, que o desemprego é sempre voluntário, intensificando a necessidade de alterar a cultura política ao estender o campo da responsabilidade pessoal e corporativa e incentivar maior eficiência, iniciativa individual/corporativa e inovação.

As organizações afirmam buscar mais competitividade, mais conhecimento, menos treinamento e mais educação. Esperam que os trabalhadores tenham capacidade de agir de acordo com as situações que se apresentam, atendendo às necessidades do mercado e moldando sua conduta com o objetivo de aumentar as competências organizacionais. Por isso, nos estudos acerca da EC temos o surgimento desse fenômeno da gestão contemporânea fundamentado também na transição paradigmática da concepção de treinamento funcional para o de educação, como uma estratégia competitiva das organizações (ALONSO-GONZALEZ; 
PERIS-ORTIZ; CHACON, 2018; EBOLI, 2004, 2016; LYTOVCHENKO, 2016; MEISTER, 1999; RADEMAKERS, 2014).

\section{O SABER NAS ORGANIZAÇÕES: A TRANSIÇÃO DO TREINAMENTO À EDUCAÇÃO CORPORATIVA}

Como expusemos anteriormente, as mudanças no mundo do trabalho levaram as organizações a institucionalizarem em suas práticas e discursos a concepção de entidades produtoras de conhecimentos e aprendizagens, necessárias ao "desenvolvimento", tanto de seus trabalhadores, quanto das demais partes interessadas (stakeholders), das competências e demais demandas de saber requeridas em suas estratégias competitivas do campo empresarial (EBOLI, 2004; MEISTER, 1999).

Nesse contexto, iniciamos este caminho pelos denominados centros de treinamento, que são estruturados nas organizações objetivando uma atuação pontual. 0 treinamento surgiu inicialmente como um processo que visava tornar os trabalhadores das organizações aptos a realizarem novas tarefas e a absorverem procedimentos, assim como a manipularem novas ferramentas de trabalho. A capacitação é focada no treinar como uma ação sistemática voltada para o aprendizado das habilidades para uma determinada função, como, por exemplo: operar uma máquina, realizar um procedimento rotineiro ou atender pessoas dentro de uma faixa estreita de responsabilidade. Tem uma natureza de característica prática e emergente, por isso distingue-se da educação. Sua prática, no entanto, nem sempre esteve alinhada aos objetivos estratégicos da organização e também não se alicerçava em diagnósticos consistentes que indicassem necessidades de conhecimentos ou habilidades requeridos pelo negócio (BORGES-ANDRADE; ABBAD; MOURÃO, 2009).

$\mathrm{Na}$ década de 80 do século passado, as áreas de Treinamento e Desenvolvimento tinham uma atuação pontual. Atuavam sob demandas e aguardavam ser acionadas pelas áreas da organização que, sempre que o faziam, buscavam soluções emergenciais, atuando pontualmente. Entretanto, essa realidade foi mudando. De meados da década de 90 em diante é percebida a grande preocupação das áreas de T\&D em se adequar para atender aos novos 
paradigmas decorrentes das mudanças globais, com impactos diretos e imediatos no modelo de formação e desenvolvimento dos profissionais e nos resultados das organizações. Neste momento, os treinamentos não estão mais agregando tanto valor aos processos e atendendo aos objetivos das organizações (MEISTER, 1999).

Para muitos estudos os treinamentos tiveram papel relevante em termos de desenvolvimento parcial das competências técnicas dos trabalhadores. Segundo Pacheco, Scofano e Beckert (2005, p. 19), por exemplo, "eles foram essenciais dentro de cada realidade organizacional; porém na perspectiva contemporânea, alguns se tornaram ineficientes". Isso acontece porque um fator negativo do treinamento está em não obter retorno a médio ou longo prazo. Por isso, avaliam que "o treinamento possui um foco bem demarcado. Em razão de seu caráter pragmático, tende a tornar o processo de aprendizagem restrito" (PACHECO; SCOFANO; BECKERT, 2005, p. 19).

Isso faz com que haja uma mudança e o foco do treinamento passa a ser orientado ao aprendizado como um todo e não mais especificamente numa função. 0 processo de treinamento foi considerado obsoleto para os padrões do que se configurou como novo modelo produtivo baseado na acumulação flexível. Para Meister (1999, p. 21), naquele momento as empresas investiram em novas modalidades com o objetivo de ensinar aos trabalhadores "o como fazer", que inicialmente era focado só nos gerentes, estendendo-se a todos posteriormente.

Diante das novas situações, a demanda por educação passa a apresentar um enorme crescimento, exigindo mudanças qualitativas e maior diversificação na construção do saber no mundo do trabalho e nos espaços organizacionais, inclusive com personalização de métodos. Nesse contexto, os trabalhadores necessitam aprender continuamente e as organizações, por sua vez, precisam enfrentar as dificuldades que lhes são apresentadas abrindo novos caminhos para a aprendizagem. O foco está em "desenvolver qualificações isoladas, para a criação de uma cultura de aprendizagem contínua, em que os funcionários 
[aprendam] uns com os outros e [compartilhem as] inovações e melhores práticas com o objetivo de solucionar problemas empresariais" (MEISTER, 1999, p. 21).

Por essa razão, as organizações avaliam implantar programas educacionais que privilegiem o desenvolvimento de atitudes, posturas e habilidades (competências) e não apenas a aquisição de conhecimentos técnicos e instrumentais.

O paradigma dominante do treinamento, da sua concepção inicial, já não é capaz de prover as necessidades de conhecimento e atualização profissional. Isso pressiona as organizações a buscarem um novo patamar nesse processo. Por conseguinte, emergem novos paradigmas voltados a concepções de programas educacionais que privilegiam o desenvolvimento de saberes voltados ao mundo do trabalho nas organizações.

Nesse sentido, surge o conceito e fundamentos do que se denominou como Educação Corporativa e seus sistemas, cujo principal e mais popular modelo é a Universidade Corporativa (UC). Para muitos estudos, os termos são usados e entendidos como sinônimos (EBOLI, 2004; MEISTER, 1999).

Para Meister (1999, p. 29), Educação Corporativa ou Universidade Corporativa "É um guarda-chuva estratégico para desenvolvimento e educação de funcionários, clientes e fornecedores, buscando otimizar as estratégias organizacionais".

De acordo com a autora, é importante compreender as forças que sustentaram o aparecimento desse fenômeno, que em essência são cinco (MEISTER, 1999):

- Organizações flexíveis: a emergência da organização não-hierárquica, enxuta e flexível, com capacidade de dar respostas rápidas ao turbulento ambiente empresarial.

- Era do Conhecimento: o advento e a consolidação da economia do conhecimento, na qual conhecimento é a nova base para a formação de riqueza nos níveis individual, empresarial ou nacional. 
- Rápida obsolescência do conhecimento: a redução do prazo de validade do conhecimento associado ao sentido de urgência.

- Empregabilidade: o novo foco na capacidade de empregabilidade/ ocupacionalidade para a vida toda em lugar do emprego para toda a vida.

- Educação para estratégia global: uma mudança fundamental no mercado da educação global, evidenciando-se a necessidade de formar pessoas com visão global e perspectiva internacional dos negócios.

Surgindo em meados do século XX como uma atividade de intenso crescimento no campo do ensino superior nas organizações, este modelo de sistema educacional teve como originária desta concepção a empresa General Electric (GE) dos Estados Unidos, que lançou a primeira Universidade Corporativa em 1945, ficando conhecida como Instituto General Motors. O seu primeiro curso foi o de graduação em Engenharia e o sucesso da GE é, por muitos, atribuído ao sucesso de sua UC. A GE transformou o seu setor de recursos humanos e treinamento em uma nova organização, responsável pela formação e atualização de seus quadros gerenciais, funcionários, fornecedores e clientes. E essa tendência foi aos poucos ganhando força no mundo corporativo (MEISTER, 1999).

A partir desse período, com as práticas e discursos das grandes corporações, principalmente do eixo euro-americano, o conceito e as concepções sobre EC foram disseminados nas demais partes do mundo, através das suas unidades de negócios. Foi popularizado no campo acadêmico-científico quando estudos começaram a ser publicados. Entre esses destacamos os de Jeanne Meister, consultora americana em EC e autora mais referenciada nos estudos acadêmicos brasileiros, principalmente com a publicação do seu livro "Corporate Universities" (MEISTER, 1999) em português (FREITAG, 2010; TOLEDO; DOMINGUES, 2018). Esse período caracteriza o início dos estudos sobre o fenômeno da EC como uma atividade de intenso crescimento no campo do management empresarial e acadêmico. Nos estudos brasileiros isso decorre principalmente através de Eboli (2004), principal referência nacional ao tema (FREITAG, 2010; TOLEDO; DOMINGUES, 2018). 
Eboli (2004) entende a EC como o conjunto de ações integradas que possibilitam o desenvolvimento de pessoas com foco nas competências empresariais e humanas que são estratégicas para o sucesso do negócio. Um sistema que tem como finalidade básica fomentar “o desenvolvimento e a instalação das competências empresariais e humanas consideradas críticas para a viabilização das estratégias de negócios" (EBOLI, 2004, p. 48), de uma forma sistemática, estratégica e contínua. Explica que a ideia de alinhamento estratégico e de continuidade, permanência na construção de saberes, é um dos aspectos marcantes relacionados às diferenças de foco e propósito entre a EC e o T\&D.

Dessa forma, a concepção de EC passa a ser compreendida e debatida como um conjunto de ações de criação do saber - não apenas de forma pontual - nas organizações, que visam desenvolver conhecimentos, habilidades e atitudes, isto é, competências individuais e organizacionais, alinhadas aos interesses estratégicos das corporações e, por consequente, capazes de incrementar seus potenciais competitivos (EBOLI, 2004, 2016; MEISTER, 1999).

Como argumenta Eboli (2004), corroborando com Meister (1999), a EC está para o conceito de competências, como os tradicionais centros de treinamento estiveram para o conceito de cargo. Nesse contexto, aprendizagem, formação e gestão de competências são conceitos centrais operacionalizados nas práticas das organizações e que se transformaram em vantagens competitivas.

De acordo com Meister (1999),

tradicionalmente, muitos departamentos de treinamento operaram como "anotadores de pedidos" - os clientes apresentam pedidos de treinamento e o departamento localiza ou cria cursos para atender a esses pedidos. Normalmente, a interação era pequena em relação aos resultados. Agora com a emergência das Universidades Corporativas, as organizações estão reestruturando os ambientes de aprendizagem, para que eles sejam pró-ativos, centralizados, determinados e realmente estratégicos por natureza. Uma mudança bastante significativa, aqui, é como a responsabilidade pelo processo de aprendizagem sai do departamento de treinamento para chegar aos gerentes empresariais (MEISTER, 1999, p. 23-24). 
Nessa lógica, com o objetivo de facilitar a compreensão das implicações da mudança de paradigma em termos de desenvolvimento de pessoas nas organizações, Eboli $(2004$, p. 50) apresenta as principais características de mudanças paradigmáticas que envolvem essa transição conceitual de um Centro de T\&D tradicional para um Sistema de Educação Corporativa (SEC), conforme Quadro 01 a seguir:

\begin{tabular}{|l|c|l|}
\hline \multicolumn{2}{|c|}{ Centro de Treinamento } & \multirow{2}{*}{ Educação Corporativa } \\
& Objetivo & Desenvolver as Competências \\
\hline Aprenvolver Habilidades & Foco & Aprendizado Organizacional \\
\hline Tático & Escopo & Estratégico \\
\hline Necessidades Individuaidual & Ênfase & Estratégias de Negócios \\
\hline Interno & Público & Interno e Externo \\
\hline Espaço Real & Local & Espaço Real e Virtual \\
\hline Aumento das Habilidades & Resultado & Aumento da Competitividade \\
\hline
\end{tabular}

Quadro 01: Mudança de paradigma de Centro de T\&D para Educação Corporativa Fonte: Eboli (2004, p. 50).

Outros estudos corroboram essas transições. Para Nisembaum (1998), por exemplo, as diferenças entre a Universidade Corporativa e um Centro de Treinamento tradicional são acentuadas em: postura proativa; o estabelecimento de uma filosofia de aprendizagem centralizada; as ações de aprendizagem customizadas; opera como uma unidade de negócios; a utilização racional do investimento em educação; a continuidade dos esforços de treinamento; a relevância que a direção da empresa dá ao trabalho por ela realizado.

Outro exemplo pode ser tomado em Ricardo (2007, p. 07), segundo a qual a Educação Corporativa visa "desenvolver processos de aprendizagem continuada que permitam o envolvimento de toda a cadeia de produção com o destino da organização e compromisso com as estratégias de negócios da empresa"; diferentemente dos Centros de T\&D, que é focado no treinar como uma ação sistemática voltada para o aprendizado das habilidades 
para uma determinada função como operar uma máquina, realizar um procedimento rotineiro ou atender pessoas dentro de uma faixa estreita de responsabilidade.

Logo, esses estudos caracterizam a EC como uma "evolução" das atividades formativas dos tradicionais processos de T\&D para sistemas de qualificação de pessoal mais estratégicos e abrangentes, numa dimensão de novo sistema de inovação de aprendizagem e de gestão de conhecimento, os quais seriam menos táticos e mais efetivos e alinhados a gestão de competências e ao planejamento estratégico da organização. Nessa concepção haveria então um processo evolutivo, no sentido de "sucesso" e "positividade", dos processos de qualificação e formação dos recursos humanos das empresas, que passariam dos tradicionais centros de T\&D para unidades de educação que poderiam evoluir e se estruturar como verdadeiros centros universitários no interior das grandes corporações.

Por esta razão, para os campos do management e dos estudos acerca do tema EC, esse paradigma mudou e vem mudando. Para fundamentar esta concepção, explicam que aprendizagem organizacional, gestão do conhecimento e gestão de competências são conceitos centrais operacionalizados nas práticas das organizações contemporâneas, visando resultados e vantagens competitivas (ALONSO-GONZALEZ; PERIS-ORTIZ; CHACON, 2018; EBOLI, 2004, 2016; LYTOVCHENKO, 2016; MEISTER, 1999; MUNDIM; RICARDO, 2009; RADEMAKERS, 2014; WHEELER, 2005).

De forma geral, os estudos abordam a EC como um sistema que objetiva desenvolver processos de aprendizagem continuada, através do envolvimento da cadeia de produção e objetivos organizacionais, com foco nas estratégias de negócios de cada respectiva organização. Entende-se, assim, que os estudos defendem que o uso intencional e sistêmico de ações educacionais em espaços organizacionais, como concebe o conceito, práticas e discursos de EC, é uma busca de consolidar as organizações como criadoras de conhecimentos, visando gerar resultados através dos seus trabalhadores, muito embora com foco no ensino específico de seus interesses de negócios e não no sentido de "formação indispensável ao exercício da cidadania" (KUENZER; GRABOWSKI, 2006, p. 298), como se 
defende nos sistemas e políticas públicas de ensino formal da educação, inclusive na educação profissionalizante. Logo, a educação é uma perspectiva de novos caminhos de construção do saber a serem estimulados, incorporados e aprimorados no mundo do trabalho, a partir de sua lógica de mercado (LAVAL, 2004).

Nesse contexto, é interessante refletir então sobre a exaltação de habilidades conceituais e abstratas em relação à qualificação, competências e formação profissionais. Essa nova configuração recai também sobre o sistema educacional formal, com mais exigências no sentido de reformulações curriculares que se integrem as necessidades do mercado de trabalho, a flexibilização e a polivalência (KUENZER; GRABOWSKI, 2006). Isso decorre de uma construção contemporânea ancorada no contexto ideológico histórico do "novo espírito do capitalismo" (BOLTANSKI; CHIAPELLO, 2009).

No novo "espírito do capitalismo" é a ideologia que justifica o comprometimento com os pressupostos do capitalismo, os quais se situam entre o utilitarismo econômico e a responsabilidade social, como ocorre com os pressupostos da economia baseada no conhecimento, por exemplo, e que fundamentam os princípios da EC, especialmente nas grandes empresas na contemporaneidade. Estas, por um lado, incorporam o papel de organizações educadoras, justificado principalmente para suprir as deficiências da formação prestada pelas instituições de ensino em atender as demandas do mercado (EBOLI, 2004; MEISTER, 1999). Por outro, exigem um alto nível de envolvimento e empregabilidade de seus trabalhadores.

No entanto, Boltanski e Chiapello (2009) explicam que o nível de qualidade desse compromisso é tomado como um problema, haja vista que não depende apenas dos estímulos econômicos, mas principalmente, também, da criação de perspectivas de aumento das vantagens coletivas derivadas do sistema. Essas perspectivas, por sua vez, ocorrem de acordo com sua fase histórica em determinado tempo e lugar. Por essa razão, tomamos esse "espírito" como gênese do sustentáculo simbólico das concepções ideológicas da EC, principalmente pelos deslocamentos espaciais e temporais de seus pressupostos e práticas. 
Destacam que a ideologia é um sistema de ideias, valores e crenças que busca explicar uma determinada ordem política, legitimar hierarquias e relações de poder existentes e preservar identidades de grupo. Dessa forma, associam a ideologia ao conceito de legitimidade de Weber, segundo o qual a dominação e a conformidade são necessárias para criar a crença nos dominados quanto a legitimidade dos dominantes (BOLTANSKI; CHIAPELLO, 2009). Nessa lógica, temos as ideologias gerencialistas que regem as relações de dominação do mundo do trabalho, e, em específico neste estudo, da gestão da EC enquanto instrumento responsável, "juntamente com a gestão por resultados, pela internalização do controle nos sujeitos, não mais nos processos, visto que a flexibilidade assim o exige" (FARIA; LEAL, 2007, p. 241).

Essa lógica também se insere, como explicam Wood Júnior, Tonelli e Cooke (2011, p. 237), no discurso da neocolonização das teorias gerenciais acerca da gestão de recursos humanos (GRH), decorrente do período pós anos 80, e que se caracteriza, entre outros aspectos, pela "renovação da ideologia do management e pela adoção maciça de novos modelos e práticas de GRH". Nesse contexto, esse discurso diz respeito à adoção de uma nova retórica ao discurso colonialista da GRH, refletindo as mudanças ocorridas como: a expansão das atividades das áreas de T\&D, que passaram a adotar frequentemente o rótulo de universidades corporativas; a introdução de novos temas e o alinhamento das políticas e práticas de GRH com a estratégia de negócios.

Por essa razão, ressalta-se que essas questões paradigmáticas da EC levantam críticas em outros estudos, de diversos campos das ciências sociais e humanas (ÉSTHER, 2017; FARIA; LEAL, 2007; QUARTIERO; BIANCHETTI, 2005; KUENZER; GRABOWSKI, 2006), o que só reforça a relevância de manter os debates e estudos acadêmico-científicos sobre o tema.

\section{CONSIDERAÇÕES FINAIS}

0 verbo "tecer" apresenta alguns significados gramaticais que correspondem a: entrelaçar; pôr determinada organização; compor algo, entrelaçando materiais diversos; e tantos outros, inclusive em sentidos figurados, tal como: fazer existir como resultado de uma 
atividade mental; compor, criar (MICHAELIS, 2015). Foi seguindo essa trilha de significados e sentidos que buscamos desenvolver neste artigo nosso objetivo de entrelaçar alguns fios teóricos dos paradigmas dominantes e emergentes nos campos das ciências e das práticas organizacionais, visando refletir sobre as possibilidades de criação e transformação do saber no mundo do trabalho e nos diversos espaços sociais.

Neste caso, especificamente, buscamos entrelaçar uns fios que nos conduzissem a tecer um entendimento das transições paradigmáticas que envolvem as construções do saber nos espaços organizacionais. Essas transições, por sua vez, advém dos processos tradicionais de treinamento nas organizações, tomados como paradigmas dominantes da era moderna, considerados assim como superados na sociedade do conhecimento, entendida em suas características pelo período da pós-modernidade e por novos paradigmas emergentes de criação do conhecimento e novas exigências aos trabalhadores, como ocorre com a concepção dos sistemas de educação corporativa.

Diante das transformações no mercado e nas relações de trabalho, quanto as exigências de um trabalhador de "novo tipo", essas transições paradigmáticas disseminam um conjunto de orientações, pregações e aconselhamentos aos trabalhadores. É um discurso que informa acerca das mudanças no mundo do trabalho, procurando dar legitimidade às estratégias gerenciais objetivando adaptação, aceitação, comprometimento, ao mesmo tempo que estimula novos modos de ser e agir no trabalho.

Como tecemos, as transições e controvérsias paradigmáticas que envolvem essas questões surgem com os atuais cenários de competição e velocidade tecnológica impostos ao mundo do trabalho. Isso impulsiona as organizações a buscar desenvolver o conhecimento e o aprendizado permanente dos trabalhadores e também de outros parceiros de seus interesses, por considerarem esta estratégia como uma das principais vantagens competitivas de uma organização na sociedade contemporânea. Nesse sentido, os estudos afirmam que não é de se estranhar a ênfase dada aos sistemas de educação corporativa, principalmente pelas grandes corporações ou pelas organizações com alto nível de inovação tecnológica. Este é um conceito 
empregado atualmente também por muitas organizações não empresariais, como as do setor público e instituições de ensino superior, por exemplo.

No entanto, faz-se necessário desenvolver também competências críticas do negócio e da cultura corporativa nesses sistemas considerados educativos. Diante de análises de vertentes críticas, constata-se que os princípios da EC, assim como as concepções anteriores de treinamento enquanto processos de capacitação dos trabalhadores, estão assentados numa relação ideológica e de poder hierárquico do mundo do trabalho. Nesse sentido, baseiam-se na gestão do fluxo de dominação do conhecimento tácito e subjetivo do capital humano ou capital intelectual das organizações, através de uma direção verticalizada, que se origina das ideologias modernas capitalistas de doutrinação e controle dos trabalhadores (BOLTANSKI; CHIAPELLO, 2009).

E que podem, no caso da EC, serem "mais do mesmo". A tão propalada conquista de autonomia dos trabalhadores, redução de burocracia, cultura participativa, são realmente mudanças nas características do trabalho ou são "o mesmo samba de uma nota só"? Desde que se cumpram as metas estabelecidas, a autonomia para executar o trabalho pode ser mantida, mas os resultados, sempre os resultados, caracterizam a pressão em torno do trabalho, ideologicamente situado entre o sucesso e o fracasso profissional.

Quanto a essas questões, uma outra análise importante a ser ressaltada é o sentido aparente desses discursos, que representa a eliminação de marcadores explícitos de hierarquia e de assimetria de poder entre pessoas com poder institucional desigual, como é próprio das relações no mundo do trabalho. Isso deve ser observado, uma vez que diversos tipos de marcadores tendem a ser eliminados, tais como: as formas assimétricas de tratamento, os diretivos diretos, como os imperativos e as assimetrias no direito de fazer certos tipos de contribuição (FAIRCLOUGH, 2001). É a lógica, por exemplo, do uso e naturalização de sentidos de expressões como "colaborador" ou "parceiro", que as teorias e práticas do campo da gestão, principalmente da gestão de pessoas, implantaram ou, no caso da EC, da "igualdade" de oportunidades de ações "educacionais" e de "desenvolvimento" do 
trabalhador promovidas pelas organizações empregadoras. Nessa linha, Hassard (1993) fornece pistas para interpretações a partir do que ele considera como epistemologia pósmoderna, que sugere que o mundo é constituído por nossas linguagens compartilhadas e apenas a partir da interpretação de discursos é que podemos conhecê-los.

Não se deve esquecer que os envolvidos nesses processos são sujeitos sociais, com identidades próprias que as diferem umas das outras e que, portanto, precisam ser respeitados por isto. Daí a importância de compreender os sentidos e (res)significações do saber empregados na concepção de "educação" em espaços organizacionais. Dessa forma, educar para o negócio ou trabalho (KUENZER; GRABOWSKI, 2006), não deve significar desenvolver um saber dominante e utilitarista da capacidade reflexiva, crítica e emancipatória dos sujeitos (FAIRCLOUGH, 2001; LAVAL, 2004). Por isso mesmo, refletir sobre os diversos entrelaçamentos que podem ser trilhados neste caminho nos parece relevante aos debates dos diversos campos das ciências e, em nosso caso, específico, da administração e dos estudos organizacionais.

Nesse sentido, à luz das transições paradigmáticas dos estudos de Boaventura Santos, entender a transição de uma modernidade que fragmenta o saber para uma pós-modernidade que ainda é incerta (SANTOS, 2009) traz motivos fundamentais para a reflexão da educação nos espaços organizacionais. Deve ceder lugar a um projeto que possibilite a imersão de diferentes saberes e "visões de mundo" que contribuam aos valores éticos, dos conhecimentos práticos e dos saberes tradicionais. Sendo assim, questionar o paradigma da EC, em tempos e espaços contemporâneos, requer entendê-lo enquanto paradigma dominante do saber nos espaços organizacionais e de suas (inter)relações em outros campos sociais. É preciso compreender este fenômeno das práticas e discursos do campo organizacional como um objeto epistemológico que requer questionamentos interdisciplinares críticos.

Nossos argumentos articulam-se, dessa forma, corroborando com os estudos de Medeiros e Teixeira $(2014,2018)$, pela perspectiva de uma agenda de novos estudos, teóricos 
e empíricos, a serem desenvolvidos a partir da articulação do pensamento de Boaventura Santos para os estudos da educação corporativa, como uma perspectiva crítica ao pensamento hegemônico funcionalista que é desenvolvido na maioria dos estudos deste fenômeno, nos campos organizacional e acadêmico (DEROSA; FREIRE, 2017; FREITAG, 2010; TOLEDO; DOMINGUES, 2018). Assim como uma alternativa para compreendê-lo a partir das relações de poder envolvidas nessas práticas de construção do saber; do papel das tecnologias digitais e paradigmas emergentes nos processos de aprendizagem desses sistemas educacionais. E a partir das discussões de sua construção sócio-histórica, dominante das grandes corporações transnacionais do eixo euro-americano, com as reflexões da (des)colonialidade e pós-colonialismo do saber, propostas pelas epistemologias do sul (SANTOS; ARAÚJO; BAUMGARTEN, 2016; MIGNOLO, 2005, 2017; SANTOS; MENESES, 2009).

\section{REFERÊNCIAS}

ALONSO-GONZALEZ, A; PERIS-ORTIZ, M.; CHACON, L. A. P. Corporate universities as a new paradigm and source of social innovation, sustainability, technology and education in the XXI century. In: PERIS-ORTIZ; GOMEZ; MARQUEZ (Ed(s).). Strategies and best practices in social innovation. Springer, Cham, 2018. p. 153-169.

ALPERSTEDT, G. D.; ANDION, C. Por uma pesquisa que faça sentido. RAE-Revista de Administração de Empresas, v. 57, n. 6, p.626-631, 2017. Disponível em: http://dx.doi.org/10.1590/s0034-759020170609. Acesso em: 01 mar. 2019.

BOLTANSKI, L.; CHIAPELLO, E. O novo espírito do capitalismo. São Paulo: WMF Martins Fontes, 2009.

BORGES-ANDRADE, J. E.; ABBAD, G. S.; MOURÃO, L. Treinamento, desenvolvimento e educação em organizações e trabalho. Porto Alegre: Artmed, 2009.

BURRELL, G.; MORGAN, G. Sociological paradigms and organisational analysis: elements of the sociology of corporate life. Aldershot. UK: Ashgate, 2005.

CASTELLS, M. A sociedade em rede. São Paulo: Paz e Terra, 1999.

CLEGG, S. Modern organizations: Organization studies in the postmodern world. Sage, 1990. 
COOPER, R.; BURRELL, G. Modernism, postmodernism and organizational analysis: An introduction. Organization Studies, v. 9, ed. 1, 1988, p. 91-112. Disponível em: https://journals.sagepub.com/doi/10.1177/017084068800900112. Acesso em 31 jul. 2020.

COUTINHO, C. P.; LISBÔA, E. S. Sociedade da informação, do conhecimento e da aprendizagem: desafios para educação no século XXI. Revista de Educação, v. 18, n. 1, p. 522, 2011. Disponível em: http://revista.educ.ie.ulisboa.pt/arquivo/vol_XVIII_1/artigo1.pdf. Acesso em: 02 mar. 2019.

CRUZ, M. H. S. Trabalho, gênero, cidadania: tradição e modernidade. São Cristóvão: Editora UFS; Aracaju: Fundação Oviêdo Teixeira, 2005.

DEROSA, F. M.; FREIRE, P. de Sá. As funções da avaliação de aprendizagem nas universidades corporativas: uma análise bibliométrica. In: SIMPÓSIO, 2017, Florianópolis. Anais do 3o Simpósio Avaliação da Educação Superior, Florianópolis: UFSC, 2017. Disponível em: https://repositorio.ufsc.br/bitstream/handle/123456789/179393/101_00786\%20\%20ok.pdf?sequence=1. Acesso em: 06 mar. 2018.

EBOLI, M. Educação Corporativa no Brasil: mitos e verdades. São Paulo: Ed. Gente, 2004.

EBOLI, M. Educação corporativa nos novos cenários empresariais. GV-executivo, v. 15, n. 2, p. 20-24, 2016. Disponível em: https://rae.fgv.br/gv-executivo/vol15-num2-2016/educacaocorporativa-nos-novos-cenarios-empresariais. Acesso em: 02 mar. 2019.

ÉSTHER, A. B. A universidade como universidade corporativa global? 0 caso da formação em Administração. GIGAPP Estudios Working Papers, v. 4, n. 60-65, p. 92-195, 2017. Disponível em: http://www.gigapp.org/ewp/index.php/GIGAPP-EWP/article/view/49. Acesso em: 03 mar. 2019.

FAIRCLOUGH, N. Discurso e mudança social. Brasília: Editora Universidade de Brasília, 2001.

FARIA, J. H. de; LEAL, A. P. Do Treinamento à Universidade Corporativa: ideologia, dominação e controle. In: FARIA, J. H. de (Org.). Análise Crítica das Teorias e Práticas

Organizacionais. São Paulo: Atlas, 2007. p. 167-189. Disponível em: http://eppeo.pro.br/livro-analise-critica-das-teorias-e-praticas-organizacionais-disponivelpara-download/. Acesso em: 27 nov. 2018.

FERRETI, C. J. Considerações sobre a apropriação das noções de qualificação profissional pelos estudos a respeito das relações entre trabalho e educação. Revista Educação e Sociologia, Campinas, vol. 25, no 87, p. 401-422, 2004. Disponível em: https://www.scielo.br/scielo.php?pid=S0101$3302004000200006 \&$ script=sci_arttext\&tlng=pt. Acesso em: 28 jul. 2020. 
Anicleide Silva, Florence Heber e Izabel D'Ambrosio

Do Treinamento e Desenvolvimento para a Educação Corporativa: transições paradigmáticas

na construção do saber nos espaços organizacionais

FREITAG, B. B. O desenvolvimento da Educação Corporativa no Brasil. In: SEMINÁRIO, XIII, 2010, São Paulo. Anais dos Seminários em Administração. São Paulo, 2010.

GATTI, B. A. Pesquisa, educação e pós-modernidade: confrontos e dilemas. Cadernos de pesquisa, v. 35, n. 126, p. 595-608, 2005. Disponível em:

http://www.scielo.br/pdf/cp/v35n126/a04n126.pdf. Acesso em: 02 mar. 2019.

HABERMAS, J. Conhecimento e Interesse. In: BENJAMIN, W.; HORKHEIMER, M.; ADORNO, T. W.; HABERMAS, J. Textos escolhidos. 2. ed. São Paulo: Abril Cultural, 1983, p. 278-312.

HARVEY, D. Condição pós-moderna: uma pesquisa sobre as origens da mudança cultural. 17. ed. São Paulo: Edições Loyola, 2008.

HASSARD, J. Postmodernism and organization. In: Sociology and organization theory. Cambridge: Cambridge University Press, 1993.

JESSOP, B. Cultural political economy, the knowledge-based economy, and the state. In: BARRY, A.; SLATER, D. Technological Economy. London: Routledge, 2005. p. 152-174.

KUENZER, A. Z.; GRABOWSKI, G. Educação Profissional: desafios para a construção de um projeto para os que vivem do trabalho. Perspectiva, v. 24, n. 1, p. 297-318, 2006. Disponível em: https://periodicos.ufsc.br/index.php/perspectiva/article/download/ 10762/10269. Acesso em: 27 set. 2019.

KUHN, T. S. A estrutura das revoluções científicas. 11. ed. São Paulo: Perspectiva, 2011.

LAVAL, C. A Escola não é uma empresa: o neo-liberalismo em ataque ao ensino público. Londrina: Editora Planta, 2004.

LEAL, R. S. As dimensões da racionalidade e os estudos organizacionais: a mediação entre a modernidade e a pós-modernidade. 0\&S, v.9, n. 25, p. 77-91, set./dez., 2002. Disponível em: https://www.scielo.br/scielo.php?pid=S1984-92302002000300005\&script=sci_arttext. Acesso em: 27 jul. 2020.

LYTOVCHENKO, I. Corporate university as a form of employee training and development in American companies. Advanced education, p. 35-41, 2016. Disponível em: http://ae.fl.kpi.ua/article/view/62280. Acesso em: 27 nov. 2018.

MARCONDES, D. A crise de paradigmas e o surgimento da modernidade. In: BRANDÃO, Z. (Org.). A crise dos paradigmas e a educação. 9. ed. São Paulo: Cortez, 2005. p. 14-29.

MEDEIROS, A. L.; TEIXEIRA, M. L. M. Gerenciando pessoas, mas com que paradigma?. Revista Brasileira de Estudos Organizacionais. Florianópolis, v. 1, n. 2, p. 212-230, 2014. 
MEDEIROS, A. L.; TEIXEIRA, M. L. M. A Potencialidade do pensamento de Boaventura Santos para os Estudos Organizacionais. Revista de Ciências da Administração, v. 20, n. 50, p. 166177, 2018. Disponível em: http://www.spell.org.br/documentos/ver/50734/apotencialidade-do-pensamento-de-boaventura-santos-para-os-estudos-organizacionais/i/ptbr. Acesso em: 09 mai. 2019.

MEISTER, J. C. Educação Corporativa. São Paulo: Makron Books, 1999.

MICHAELIS, Dicionário da Língua Portuguesa. Dicionário online Uol. Editora Melhoramentos, 2015. Disponível em: https://michaelis.uol.com.br/moderno-portugues/ creditos/. Acesso em: 10 mai. 2019.

MIGNOLO, W. D. A colonialidade de cabo a rabo: o hemisfério ocidental no horizonte conceitual da modernidade. A colonialidade do saber: eurocentrismo e ciências sociais. Perspectivas latino-americanas. Buenos Aires: Clacso, p. 71-103, 2005. Disponível em: http://biblioteca.clacso.edu.ar/gsdl/collect/clacso/index/assoc/D1201.dir/6_Mignolo.pdf. Acesso em: 25 jul. 2020.

MIGNOLO, W. D. Colonialidade: o lado mais escuro da modernidade. Revista Brasileira de Ciências Sociais, v. 32, n. 94, p. 1-17, 2017. Disponível em: https://www.scielo.br/scielo.php?pid=S010269092017000200507\&script=sci_abstract\&tlng =pt. Acesso em: 25 jul. 2020.

MOTTA, A. C. de G. D. Estudos organizacionais frente aos paradigmas contemporâneos. REASU-Revista Eletrônica de Administração da Universidade Santa Úrsula, v. 1, n. 2, 2017. Disponível em: http://revistas.icesp.br/index.php/REASU/article/ view/247. Acesso em: 09 mai. 2019.

MOTTA, A. C. de G. D.; THIOLLENT, M. Abordagem crítica nos estudos organizacionais no Brasil: grupos de pesquisa e iniciativas em universidades. In: CONGRESSO, IV, 2016, Escola de Administração da UFRGS. Anais do Congresso Brasileiro de Estudos Organizacionais. CBEO, 2016. Disponível em: https://anaiscbeo.emnuvens.com.br/cbeo/article/view/156. Acesso em: 25 set. 2018.

MORGAN, G. Paradigmas, Metáforas e Resolução de Quebra-cabeças na Teoria das Organizações. RAE-Revista de Administração de Empresas, v. 45, n. 1, p. 58-71, 2005. Disponível em: https://rae.fgv.br/rae/vol45-num1-2005/paradigmas-metaforas-resolucaoquebra-cabecas-na-teoria-organizacoes. Acesso em: 10 mai. 2019.

MUNDIM, A. P. F; RICARDO, E. J. (Orgs.). Educação corporativa: fundamentos e práticas. Rio de Janeiro: Qualitymark, 2009.

NISEMBAUM, H. Universidade corporativa. Ser humano. São Paulo, v. XXXII, n.131, p. 40-41, abr. 1998. 
PACHECO, L.; SCOFANO, A. C.; BECKERT, M. Capacitação e Desenvolvimento de Pessoas. Rio de Janeiro: Ed. FGV, 2005.

PARKER, M. Critique in the name of what: postmodernism and critical approaches to organization. Organization Studies, v. 16, n. 4, p. 553-564, 1995. Disponível em: https://journals.sagepub.com/doi/10.1177/017084069501600401. Acesso em: 30 jul. 2020.

PLASTINO, C. A. A crise dos paradigmas e a crise do conceito de paradigma. In: BRANDÃO, Z. (Org.). A crise dos paradigmas e a educação. 9. ed. São Paulo: Cortez, 2005. p. 32-47.

QUARTIERO, E. M.; BIANCHETTI, L. (Org(s).). Educação corporativa: mundo do trabalho e do conhecimento: aproximações. São Paulo: Cortez, 2005.

RADEMAKERS, M. Corporate universities: drivers of the learning organization. Routledge, 2014.

RICARDO, E. J. (Org.). Gestão da Educação Corporativa. São Paulo: Pearson Prentice Hall, 2007.

SANTOS, B. S. Pela mão de Alice: o social e o político na pós-modernidade. 3. ed. São Paulo: Cortez, 1997.

SANTOS, B. S. Do pós-moderno ao pós-colonial. E para além de um e de outro. Travessias, UC, Coimbra, n. 6/7, p. 15-36, 2008. Disponível em: https://estudogeral.sib.uc.pt/handle/10316/43227. Acesso em 31 jul. 2020.

SANTOS, B. S. Um discurso sobre as ciências. 6. ed. São Paulo: Cortez, 2009.

SANTOS, B. S.; MENESES, M. P. Epistemologias do sul. Coimbra: Almedina, 2009.

SANTOS, B. S.; ARAÚJO, S.; BAUMGARTEN, M. As Epistemologias do Sul num mundo fora do mapa. Sociologias, v. 18, n. 43, p. 14-23, 2016. Disponível em:

https://www.scielo.br/scielo.php?pid=S1517-45222016000300014\&

script=sci_arttext\&tlng= pt. Acesso em: 20 jul. 2020.

SANTOS, E. H. Ciência e cultura: uma outra relação entre saber e trabalho. In: Trabalho \& Educação, Belo Horizonte, n. 7, p. 120-130, 2000. Disponível em: https://periodicos.ufmg.br/index.php/trabedu/article/view/9207. Acesso em: 30 maio 2019.

SANTOS FILHO, J. C.; GAMBOA, S. S. (Org(s).). Pesquisa educacional: quantidade, qualidade. 6. ed. São Paulo: Cortez, 2007. 
SERVA, M.; CAITANO, D.; SANTOS, L.; SIQUEIRA, G. A análise da racionalidade nas organizações - um balanço do desenvolvimento de um campo de estudos no Brasil. Cadernos Ebape. BR, v. 13, n. 3, p. 414-437, jul-set, 2015. Disponível em: https://www.redalyc.org/ pdf/3232/323239879003.pdf. Acesso em: 28 jul. 2019.

TOLEDO, G. S.; DOMINGUES, C. R. Produção sobre educação corporativa no Brasil: um estudo bibliométrico. Revista de Gestão e Secretariado, v. 9, n. 1, 2018. Disponível em: https://revistagesec.org.br/secretariado/article/view/755. Acesso em 27 jan. 2019.

WHEELER, K. The corporate university workbook: launching the 21st century learning organization. San Francisco: John Wiley \& Sons, 2005.

WOOD JUNIOR, T.; TONELLI, M. J.; COOKE, B. Colonização e neocolonização da gestão de recursos humanos no Brasil (1950-2010). RAE - Revista de Administração de Empresas, v. 51, n. 3, p. 232-243, 2011. Disponível em: http://bibliotecadigital.fgv.br/ojs/ index.php/rae/article/view/30967. Acesso em: 29 mai. 2018.

ZARIFIAN, P. Objetivo competência: por uma nova lógica. São Paulo: Atlas, 2001. 